\title{
Efficacy of Morphological Characters for Varietal Identification of Chilli
}

\author{
J. Padma ${ }^{1}$, S. Anbu' ${ }^{2}$ and K. Sivasubramaniam ${ }^{1} *$ \\ ${ }^{1}$ Department of Seed Science and Technology, Agricultural College and Research Institute, \\ Madurai, Tamil Nadu, India \\ ${ }^{2}$ Department of Biochemistry, Sacred Heart College (Autonomous), Tirupattur, \\ Vellore -635601, India \\ *Corresponding author
}

\section{A B S T R A C T}

The present study was aimed to identify the chilli varieties through its morphological characters identification. Tamil Nadu Agriculture University (TNAU) released chilli

\begin{tabular}{|l|}
\hline Ke y w o r d s \\
Chilli, \\
$\begin{array}{l}\text { Morphological } \\
\text { characters, } \\
\text { Identification, } \\
\text { Anthocyanin. }\end{array}$ \\
\hline Article Info \\
\hline $\begin{array}{l}\text { Accepted: } \\
\text { 18 January } 2017 \\
\text { Available Online: } \\
\text { 10 February } 2017\end{array}$ \\
\hline \hline
\end{tabular}
varieties viz., CO1, CO2, K1, K2, KKM1, PKM1, PMK1, PLR1, CCH1(hybrid), CA97 (male) and $\operatorname{Sin} 1$ (female) were used. The experiment was carried out during the period from August 2011 to February 2012. There are 33 morphological characters (plant height, leaf density, flower position etc.,) were studied in identification. Among the above, only 8 qualitative morphological characters (Intensity of anthocyanin coloration of nodes, stem pubescence, plant growth habit, leaf color, leaf pubescence, flower position, anther colour and calyx annular constriction) and 3 qualitative characters (plant height, leaf length and leaf width) were found as the important morphological characters for identification. Other characters (Seedling: Anthocyanin colouration of hypocotyl, hypocotyl pubescence, Stem colour, Plant: Anthocyanin etc.,) were of secondary importance for identification of varieties. Some of the characters were recorded in quantitatively and the cluster was formed from the recorded quantitative data, based on similarity in the characters the varieties were grouped into three main clusters at $76 \%$ similarity level. In cluster one PMK1, PLR1 and CO2 were diverged from other genotypes at $87.5 \%$ similarity. The rest of eight genotypes formed a second cluster and third cluster showing the $80 \%$ similarity level and thus useful for varietal identification.

\section{Introduction}

Chilli (Capsicum spp.) is an important vegetable cum spice crop grown in the tropical, subtropical as well as temperate regions. India is the largest producer of chillies in the world. Its production level hovers around 1.1 million tonnes annually. India also has the maximum area dedicated to the production of this crop. The major regions where chilli is cultivated in India are Karnataka, Maharashtra, Uttar Pradesh, Punjab, Tamil Nadu, Rajasthan, Orissa, West Bengal and Madhya Pradesh. (Kumar et al.,
2011). Most of the chill varieties are local cultivars or landraces. Landraces are variable plant populations adapted to local agro climatic conditions, which are locally named, selected and maintained by the traditional farmers to meet their social, economic, cultural and ecological needs (Hasan et al., 2014).

The varietal identification and parietal purity assessment is an important parameter for the released cultivars. Cultivars are commonly 
identified on the basis of morphological differences of seed, seedling and mature plant.

Morphological evaluation of pepper germplasm accessions have been studied for most plant and fruit traits (Qaryouti et al., 2003). It has been reported the variation in cotyledon color, number of stems, stem color, stem pubescence, leaf properties, number of flowers, flower color, anthocyanin in fruit, anther color, stigma position, immature fruit color and number of fruit in chilli (Wang and Bosland, 2006). Most of the varieties or cultivars within a species can be distinguished at the fruiting stage by the shape and size of the fruits. With the introduction of Indian legislation Protection of Plant Varieties and Farmers Rights Act (PPV and FRA, 2001), the release of new crop varieties is possible only if it is distinct (D) from other varieties, uniform (U) in their characteristics and generally stable (S) over the years (DUS). Farmers and seed growers need an assurance that they are being supplied with correct seed material with known identity of a specific variety and assured quality. Thus, there is an urgent need to search for rapid and reliable methods of varietal identification. Morphological characters of both qualitative and quantitative have long been used to identify species and to discriminate between varieties. Characterization of varieties based on morphological characters are carried out with the specific characters in the field during seedling, vegetative etc., But it is expensive and time consuming process and the purity of seed will be known only after the seed developed into plant. Keeping this in view the present investigation was carried out to differentiate eleven chilli varieties based on morphological characters.

\section{Materials and Methods}

Plant materials: Total eight chilli varieties (CO1, CO2, K1, K2, KKM1, PKM1, PMK1 and PLR1) and one hybrid (CCH1) and its parents of CA97 (male) and Sln1 (female) were obtained from TNAU, and the research work carried at the Agricultural College and Research Institute, Madurai during August 2011 and 2012.

Field experiments: The six weeks old seedlings were transplanted using $60.0 \mathrm{~cm} \mathrm{x}$ $45.0 \mathrm{~cm}$ plant to plant and row to row on the basis of a randomized complete block design. NPK fertilizers at rate of 90:60:60 kg/ ha were applied. There are 33 morphological characters such as genotype on anthocyanin colouration of hypocotyl, Hypocotyl pubescence, Cotyledonous leaf colour, Cotyledonous leaf shape, Stem colour, anthocyanin coloration of nodes, intensity of anthocyanin coloration of nodes, Nodal anthocyanin, Stem pubescence etc., were recorded on five randomly selected plants.

Cluster analysis: The quantitative morphological traits observed subjected to cluster analysis. The genetic association between genotypes was evaluated by calculating the similarity matrix coefficient for pairwise comparisons based on the morphological characters. Pair wise similarity matrices were generated by Jaccard's coefficient of similarity (Jaccard, 1908) by using SIMQUAL format of NTSYS-PC (Rohlf, 2002). A dendrogarm was constructed by using the unweighted pair group method on arithmetic average (UPGMA) with SHAN module.

\section{Results and Discussion}

Morphological characters: Table 1 shows the 33 morphological characters of 11 chilli genotypes. Among the above, only 8 morphological characters like intensity of anthocyanin coloration of nodes, plant growth habit, leaf colour, leaf pubescence, flower position, Anther colour and calyx annular constriction were useful in the varietal 
identification (Table 2). The intensity of anthocyanin colouration of nodes categorized the genotypes into two groups as medium and strong. PLR1 had strong pigmentation and medium in rest of the other genotypes. The stem pubescence was found to be sparse in four genotypes viz., K2, CCH1, CA97 and Sin1. The pubescence was found to be intermediate for K1, PKM1, PMK1, KKM1 whereas the rest of genotypes viz., $\mathrm{CO} 1, \mathrm{CO} 2$ and PLR1 had dense pubescence. The eleven genotypes were grouped as prostate, intermediate and erect. None of the genotypes fell under prostrate type. While, CO1, KKM1, CCH1, CA97 and Sln 1 fell under intermediate category. Whereas K1, K2, PLR1, PKM1, PMK1 and CO2 came under erect group. Leaf colour of all the genotypes was light green, green and dark green. $\mathrm{CO} 1, \mathrm{CCH} 1, \mathrm{CA} 97$ and Sln 1 were dark green. While other genotypes viz., CO2, K1, K2, KKM1, PLR1, PKM1 and PMK1 fell under light green. When considering leaf pubescence, K2, CCH1, CA97 and SIn1 has sparse pubescence, K1, PLR1, PKM1, PMK1 and KKM1 came under intermediate pubescence whereas $\mathrm{CO} 1$ and $\mathrm{CO} 2$ was dense pubescence. The eleven genotypes were grouped as pendant, intermediate and erect based on flower position. K1, K2, KKM1, PLR1, PKM1 and PMK1 were grouped as intermediate type. $\mathrm{CO} 1, \mathrm{CO} 2, \mathrm{CCH} 1, \mathrm{CA} 97$ and $\mathrm{S} \ln 1$ were grouped as erect type. In the case of anther colour, eleven chilli genotypes were grouped as white, yellow, pale blue, blue and purple. $\mathrm{CO} 1, \mathrm{~K} 1, \mathrm{~K} 2$ and PMK1 were fall under pale blue colour. CO2, PLR1, PKM1 and KKM1 were categorized under blue. Other genotypes such as $\mathrm{CCH} 1, \mathrm{CA} 97$ and Sin 1 came under purple colour. The calyx annular constriction was absent in K1, PKM1 and KKM1. CO2, K2, PLR1, PMK1, CCH1, CA97 and Sln1 were present.

Table 3 shows the qualitative characters different chilli verities. Based on plant height, genotypes were grouped into very short $(<25$ $\mathrm{cm})$, short $(25-45 \mathrm{~cm})$, medium $(45-65 \mathrm{~cm})$, long $(65-85 \mathrm{~cm})$ and extra-long $(>85 \mathrm{~cm})$. CO1, CO2, PLR1, PMK1, CCH1, CA97 and Sln1 fell under medium category and KKM1, $\mathrm{K} 1, \mathrm{~K} 2$ and PKM1 had long category. Based on leaf length, genotypes were grouped as short $(<10 \mathrm{~cm})$, medium $(10-15 \mathrm{~cm})$ and long $(>15$ $\mathrm{cm})$ categories. Among eleven genotypes, CO1, CA97, Sln1 and CCH1 were categorized under short. The genotypes viz., CO2, K1, K2, PLR1, PKM1, PMK1 and KKM1 fell under medium. The leaf width was found to be short $(<3 \mathrm{~cm})$ in three genotypes viz., CO1, CA97, Sln1 and $\mathrm{CCH} 1$. The leaf width was found to be medium (3-5 $\mathrm{cm}$ ) for $\mathrm{CO} 2, \mathrm{~K} 1, \mathrm{~K} 2$, PLR1, PKM1, PMK1 and KKM1. The morphological traits were helpful for easy separation of varieties and hybrid among the genotypes studied.

Cluster analysis: The similarity and dissimilarity occur in the morphological characters among different chilli varieties were given in table 1. Among the 33 morphological characters, 3 quantitative characters such as plant leaf length, width and plant height were taken for the cluster analysis. The dendrogram (Fig.1) depicted PMK1, PLR1 and CO2 varieties possess medium leaf length $(10-15 \mathrm{~cm})$, width $(3-5$ $\mathrm{cm})$ and medium plant height $(45-65 \mathrm{~cm})$ were diverged under the cluster I. K1, K2, PKM1 and KKM1 varieties possess medium leaf length $(10-15 \mathrm{~cm})$, width $(3-5 \mathrm{~cm})$ and long plant height $(66-85 \mathrm{~cm})$ were fall in the cluster II. CO1, CCH1, CA97 and Sln1 varieties possess short leaf length $(<10 \mathrm{~cm})$, short leaf width $(<3 \mathrm{~cm})$ and medium plant height $(46-65 \mathrm{~cm})$ were diverged under cluster III.

In chilli intensity of anthocyanin colouration of nodes categorized the genotypes into two groups as medium and strong. PLR 1 had strong pigmentation and it was medium in CO1, CO2, K1, K2, PKM1, PMK1, PLR1, KKM1, CCH1, CA97 and Sln1 genotypes. 
Similar results have also been reported by Ravi (2000). Paul et al., (2010) observed the anthocyanin colouration was present in all accessions of tomato a few days after transplanting. However, the pigmentation disappeared in the later stage of crop growth. Similarly, our study was showed anthocyanin coloration of nodes disappeared in the later stage of crop growth in all the eleven chilli genotypes. The stem pigmentation is one of the conspicuous characteristics in varietal identification. Stem pigmentation is under genetic control and it may also be affected by light intensity and temperature prevailing during the crop growth, thus resulting in variation in the degree of pigmentation in chilli genotypes.

The stem pubescence was found to be sparse in four genotypes viz., K2, CCH1, CA97 and Sln1. The pubescence was found to be intermediate for $\mathrm{K} 1$, PKM1, PMK1 and KKM1 whereas the rest of genotypes viz., $\mathrm{CO} 1, \mathrm{CO} 2$ and PLR1 had dense pubescence. Manju and Sreelathakumary, (2004) reported that most of the chilli accessions had sparse stem pubescence. Similar observations were made by Payakhapaab et al., (2012) and Manjunath Reddy (2005) in cotton genotypes. This character was highly useful for identification of genotypes.

The plant height is one of the important characteristics, which help in differentiating the genotypes as short, medium and tall. Based on plant height, CO1, CO2, PLR, PMK1, $\mathrm{CCH} 1, \mathrm{CA} 97$ and Sln1 fall under medium category $(45-65 \mathrm{~cm}), \mathrm{KKM} 1, \mathrm{~K} 1, \mathrm{~K} 2$ and PKM1 had long category $(65-85 \mathrm{~cm})$. Jain et al., (2002) in mungbean and Mate and Shelar, (2006) in sorghum varieties reported that plant height characteristics can be used for differentiation genotypes.

Plant growth habit is an important in terms of crop management because it can help in terms of defining the area for each plant. The eleven chilli genotypes were grouped as prostate, intermediate and erect. None of the genotypes fell under prostrate type. While, CO1, KKM1, $\mathrm{CCH} 1, \mathrm{CA} 97$ and Sln1 fell under intermediate category. Whereas K1, K2, PLR1, PKM1, PMK1 and $\mathrm{CO} 2$ came under erect group. The decrease in branch number would lead to erect plant growth and decreased fruit diameter and fruit weight. Sudre et al., (2010) reported that most of the chilli accessions were classified as intermediate with regard to the trait growth habit.

The present investigation, Pantone colour matching system classified leaf colour of all the genotypes were light green, green and dark green. CO1, CCH1, CA97 and Sln1 were dark green with pantone number (PMS 363). While other genotypes viz., $\mathrm{CO} 2, \mathrm{~K} 1, \mathrm{~K} 2$, KKM1, PLR1, PKM1 and PMK1 fell under light green with pantone number (PMS 362). Similar results were reported earlier Arunkumar et al., (2004) in pearl millet.

In case of leaf pubescence, K2, CCH1, CA97 and Sln1 had sparse pubescence, K1, PLR1, PKM1, PMK1 and KKM1 came under intermediate pubescence whereas $\mathrm{CO} 1$ and $\mathrm{CO} 2$ possessed dense pubescence. Sripunitha (2012) also used this trait to classify ten and fifteen varieties. Based on leaf length, genotypes $\mathrm{CO} 1, \mathrm{CA} 97, \mathrm{~S} \ln 1$ and $\mathrm{CCH} 1$ were categorized under short $(<10 \mathrm{~cm})$. The genotypes viz., CO2, K1, K2, PLR1, PKM1, PMK1 and KKM1 fell under medium category $(10-15 \mathrm{~cm})$. Similar variations and grouping of genotypes in these leaf characters were reported earlier by Prakash and Singhal (1997) in pea varieties. The leaf width was found to be short $(3 \mathrm{~cm})$ in three genotypes viz., $\mathrm{CO} 1, \mathrm{CA} 97, \mathrm{~S} \ln 1$ and $\mathrm{CCH} 1$ and medium $(3-5 \mathrm{~cm})$ for $\mathrm{CO} 2, \mathrm{~K} 1, \mathrm{~K} 2$, PLR1, PKM1, PMK1, KKM1 and CCH1. Eevera (2003) used this trait to identify the 26 rice cultivars. 
On the basis of flower position, the eleven chilli genotypes were grouped as pendant, intermediate and erect based on flower position. K1, K2, KKM1, PLR1, PKM1 and PMK1 were grouped as intermediate type. CO1, $\mathrm{CO} 2, \mathrm{CCH} 1, \mathrm{CA} 97$ and $\mathrm{Sln} 1$ were grouped as erect type. Similar variations were observed by Sonia Sood et al., (2011) in capsicum genotypes. Based on characterization by flower morphology, anther colour was pale blue in $\mathrm{CO} 1, \mathrm{~K} 1, \mathrm{~K} 2$ and PMK1 and also CO2, PLR1, PKM1 and KKM1 were categorized under blue. Other genotypes such as $\mathrm{CCH} 1, \mathrm{CA} 97$ and Sln1 came under purple. Flower morphology, including flower color, calyx constriction and the number of flowers per axil, is most used in taxonomic descriptions (Moscone et al., 2007 and Ince et al., 2009). In chilli genotypes, calyx annular constriction was absent in K1, PKM1 and KKM1 while it was present in CO2, K2, PLR1, PMK1, CCH1, CA 97 and Sln1. Similar results were observed by Sudre et al., (2010).

Table.1 Morphological characterization of chilli genotypes based on DUS guidelines

\begin{tabular}{|c|c|c|c|c|}
\hline S.No & Characters & States & Varieties & Score \\
\hline \multirow[t]{2}{*}{1} & Seedling:Anthocyanin & Absent & - & 1 \\
\hline & $\begin{array}{l}\text { colouration } \quad \text { of } \\
\text { hypocotyl }\end{array}$ & Present & $\begin{array}{l}\text { CO1, CO2, K1, K2, PLR1, PKM1, PMK1, KKM1, CCH1, CA97 and } \\
\text { Sln1 }\end{array}$ & 9 \\
\hline \multirow[t]{3}{*}{2} & \multirow[t]{3}{*}{ Hypocotyl pubescence } & Sparse & $\begin{array}{l}\text { CO1, CO2, K1, K2, PLR1, PKM1, PMK1, KKM1, CCH1, CA97 and } \\
\text { Sln1 }\end{array}$ & 3 \\
\hline & & Intermediate & - & 5 \\
\hline & & Dense & - & 7 \\
\hline \multirow[t]{3}{*}{3} & \multirow[t]{3}{*}{$\begin{array}{l}\text { Cotyledonous } \\
\text { colour }\end{array}$} & Light green & $\begin{array}{l}\text { CO1, CO2, K1, K2, PLR1, PKM1, PMK1, KKM1, CCH1, CA97 and } \\
\text { Sln1 }\end{array}$ & 1 \\
\hline & & Green & - & 2 \\
\hline & & Dark green & - & 3 \\
\hline \multirow[t]{3}{*}{4} & \multirow{3}{*}{$\begin{array}{l}\text { Cotyledonous } \\
\text { shape }\end{array}$} & Deltoid & - & 1 \\
\hline & & Ovate & - & 2 \\
\hline & & Lanceolate & $\begin{array}{l}\text { CO1, CO2, K1, K2, PLR1, PKM1, PMK1, KKM1, CCH1, CA97 and } \\
\text { Sln1 }\end{array}$ & 3 \\
\hline \multirow[t]{3}{*}{5} & \multirow[t]{3}{*}{ Stem colour } & Green & - & 1 \\
\hline & & $\begin{array}{l}\text { Green with } \\
\text { purple }\end{array}$ & $\begin{array}{l}\mathrm{CO} 1, \mathrm{CO} 2, \mathrm{~K} 1, \mathrm{~K} 2 \text {, PLR1, PKM1, PMK1, KKM1, CCH1, CA97 and } \\
\mathrm{S} \ln 1\end{array}$ & 2 \\
\hline & & Purple & - & 3 \\
\hline \multirow[t]{2}{*}{6} & \multirow{2}{*}{$\begin{array}{l}\text { Plant:Anthocyanin } \\
\text { coloration of nodes }\end{array}$} & Absent & - & 1 \\
\hline & & Present & $\begin{array}{l}\mathrm{CO} 1, \mathrm{CO} 2, \mathrm{~K} 1, \mathrm{~K} 2, \mathrm{PLR} 1, \mathrm{PKM} 1, \mathrm{PMK} 1, \mathrm{KKM} 1, \mathrm{CCH} 1, \mathrm{CA} 97 \text { and } \\
\mathrm{S} \ln 1\end{array}$ & 9 \\
\hline \multirow[t]{5}{*}{7} & \multirow{5}{*}{$\begin{array}{l}\text { Stem: Intensity of } \\
\text { anthocyanin } \\
\text { coloration of nodes }\end{array}$} & Very weak & - & 1 \\
\hline & & Weak & - & 3 \\
\hline & & Medium & $\mathrm{CO} 1, \mathrm{CO} 2, \mathrm{~K} 1, \mathrm{~K} 2, \mathrm{PKM} 1, \mathrm{PMK} 1, \mathrm{KKM} 1, \mathrm{CCH} 1, \mathrm{CA} 97$ and Sln1 & 5 \\
\hline & & Strong & PLR1 & 7 \\
\hline & & Very strong & - & 9 \\
\hline \multirow[t]{4}{*}{8} & \multirow{4}{*}{$\begin{array}{l}\text { Nodal anthocyanin } \\
\text { colour }\end{array}$} & Green & - & 1 \\
\hline & & Light purple & - & 3 \\
\hline & & Purple & $\begin{array}{l}\mathrm{CO} 1, \mathrm{CO} 2, \mathrm{~K} 1, \mathrm{~K} 2 \text {, PLR1, PKM1, PMK1, KKM1, CCH1, CA97 and } \\
\text { Sln1 }\end{array}$ & 5 \\
\hline & & Dark purple & - & 7 \\
\hline \multirow[t]{3}{*}{9} & \multirow[t]{3}{*}{ Stem pubescence } & Sparse & $\mathrm{K} 2, \mathrm{CCH} 1, \mathrm{CA} 97$ and $\mathrm{S} \ln 1$ & 3 \\
\hline & & Intermediate & $\mathrm{K} 1, \mathrm{PKM} 1, \mathrm{PMK} 1$ and KKM1 & 5 \\
\hline & & Dense & $\mathrm{CO} 1, \mathrm{CO} 2$ and PLR1 & 7 \\
\hline \multirow[t]{3}{*}{10} & \multirow[t]{3}{*}{ Plant height $(\mathrm{cm})$} & $\begin{array}{l}\text { Very short } \\
(<25 \mathrm{~cm})\end{array}$ & - & 1 \\
\hline & & $\begin{array}{l}\text { Short }(25-45 \\
\mathrm{cm})\end{array}$ & - & 3 \\
\hline & & $\begin{array}{l}\text { Medium } \\
(46-65 \mathrm{~cm})\end{array}$ & CO1, CO2, PLR1,PMK1,CCH1,CA97 and Sln1 & 5 \\
\hline
\end{tabular}




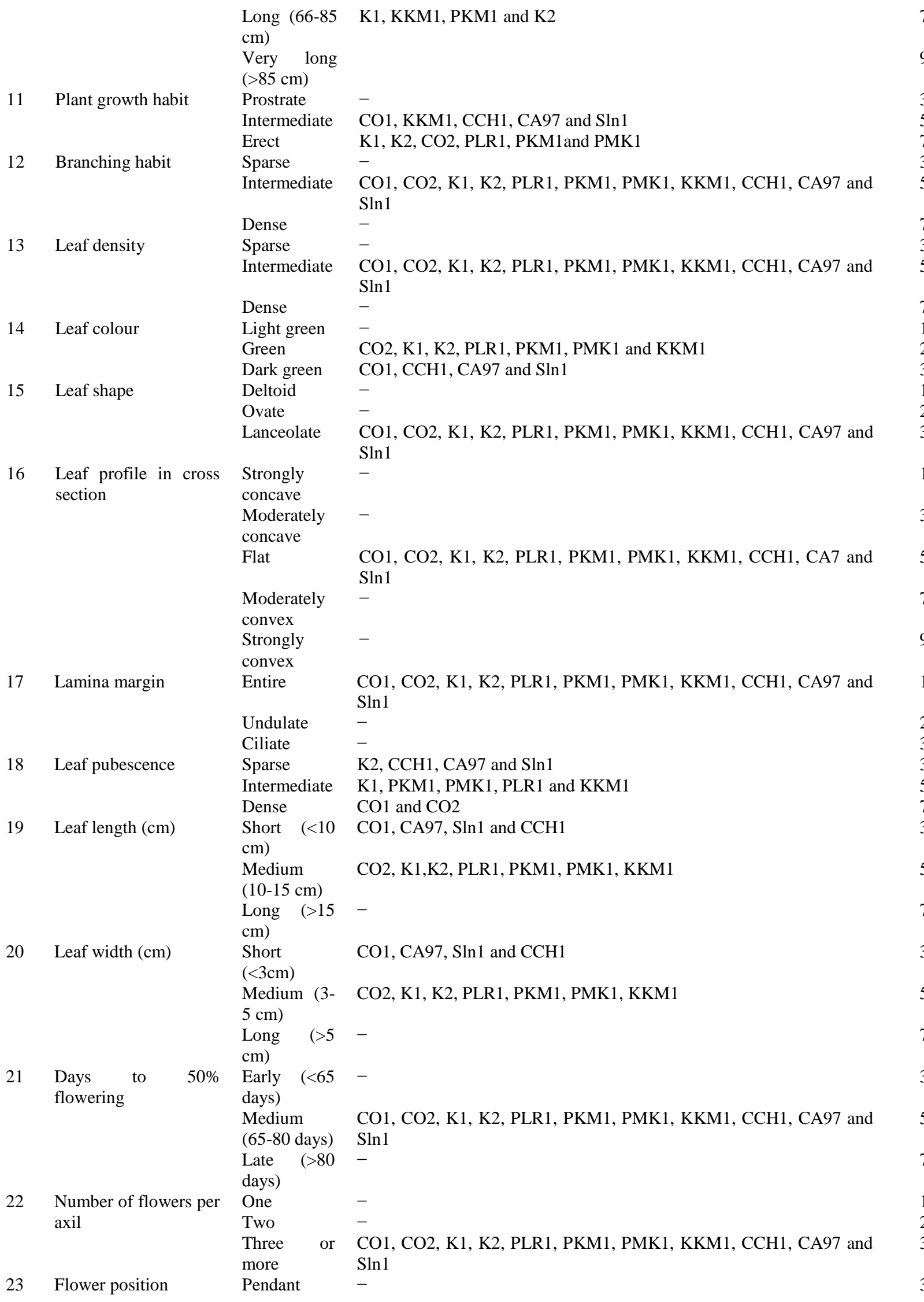


24 Corolla colour

25 Corolla shape

26 Corolla length $(\mathrm{cm})$

27 Anther colour

28 Filament colour

29 Pubescence of style

30 Calyx pigmentation

$31 \quad$ Calyx margin

32 Calyx annular constriction

33 Peduncle: Abscission layer
Intermediate

Erect

White

Light yellow

Yellow

Yellow

green

Rotate

Campanulate

Short $\quad(<1.5$

$\mathrm{cm})$

Medium (1.5

$-2.5 \mathrm{~cm})$

$\mathrm{cm}$ )

White

Yellow

Pale blue

Blue

Purple

White

Yellow

Green

Blue

Light purple

Purple

Absent

Present

Absent

Present

Entire

Intermediate

Dentate

Absent

Present

Absent

Present
K1, K2, PLR1, PKM1, PMK1 and KKM1

$\mathrm{CO} 1, \mathrm{CO} 2, \mathrm{CCH} 1, \mathrm{CA} 97$ and $\mathrm{S} \ln 1$

CO1, CO2, K1, K2, PLR1, PKM1, PMK1, KKM1, CCH1, CA97 and $\operatorname{Sin} 1$

$-$

$-$

CO1, CO2, K1, K2, PLR1, PKM1, PMK1, KKM1, CCH1, CA97 and 1 $\operatorname{Sln} 1$

$-$

CO1,CO2, K1, K2, PLR1, PKM1, PMK1, KKM1, CCH1,CA97 and 2 $\operatorname{Sin} 1$

$-$

CO1, K1, K2 and PMK1

CO2, PLR1, PKM1 and KKM1

$\mathrm{CCH} 1, \mathrm{CA} 97$ and $\operatorname{Sin} 1$

CO1, CO2, K1, K2, PLR1, PKM1, PMK1, KKM1, CCH1, CA97 and Sln 1

$-$

$-$

$-$

$-$

CO1, CO2, K1, K2, PLR1, PKM1, PMK1, KKM1, CCH1, CA97 and $\operatorname{Sin} 1$

-

CO1, CO2, K1, K2, PLR1, PKM1, PMK1, KKM1,CCH1, CA97 and 1 $\operatorname{Sin} 1$

$-$

$-$

CO1, CO2, K1, K2, PLR1, PKM1, PMK1, KKM1, CCH1, CA97 and 3

$\operatorname{Sin} 1$

$\mathrm{K} 1$, PKM1 and KKM1

CO1, CO2, K2, PMK1, PLR1, CCH1, CA97 and Sln1

CO1, CO2, K1, K2, PLR1, PKM1, PMK1, KKM1, CCH1, CA97 and

$\operatorname{Sin} 1$

(1)

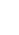

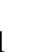


Int.J.Curr.Microbiol.App.Sci (2017) 6(2): 690-700

Table.2 Qualitative morphological characters for Chilli variety

\begin{tabular}{|c|c|c|c|c|c|c|c|c|}
\hline Genotypes & $\begin{array}{l}\text { Stem intensity of } \\
\text { anthocyanin } \\
\text { coloration of nodes }\end{array}$ & $\begin{array}{l}\text { Stem } \\
\text { Pubescence, }\end{array}$ & $\begin{array}{l}\text { Plant growth } \\
\text { habit }\end{array}$ & Leaf Color & $\begin{array}{l}\text { Leaf } \\
\text { Pubescence }\end{array}$ & Flower Position & Anther Colour & $\begin{array}{l}\text { Calyx annular } \\
\text { constriction }\end{array}$ \\
\hline $\mathrm{CO} 1$ & Medium & Dense & Intermediate & Dark Green & Dense & Erect & Pale Blue & Present \\
\hline $\mathrm{CO} 2$ & Medium & Dense & Erect & Light Green & Dense & Erect & Blue & Present \\
\hline K1 & Medium & Intermediate & Erect & Light Green & Intermediate & Intermediate & Pale Blue & Absent \\
\hline $\mathrm{K} 2$ & Medium & Sparse & Erect & Light Green & Sparse & Intermediate & Pale Blue & Present \\
\hline KKM1 & Medium & Intermediate & Intermediate & Light Green & Intermediate & Intermediate & Blue & Absent \\
\hline PKM1 & Medium & Intermediate & Erect & Light Green & Intermediate & Intermediate & Blue & Absent \\
\hline PMK1 & Medium & Intermediate & Erect & Light Green & Intermediate & Intermediate & Pale Blue & Present \\
\hline PLR1 & Strong & Dense & Erect & Light Green & Intermediate & Intermediate & Blue & Present \\
\hline $\mathrm{CCH} 1$ & Medium & Sparse & Intermediate & Dark Green & Sparse & Erect & Purple & Present \\
\hline CA97 & Medium & Sparse & Intermediate & Dark Green & Sparse & Erect & Purple & Present \\
\hline $\operatorname{Sln} 1$ & Medium & Sparse & Intermediate & Dark Green & Sparse & Erect & Purple & Present \\
\hline
\end{tabular}

Table.3 Quantitative morphological characters for Chilli variety

\begin{tabular}{llll}
\hline Genotypes & $\begin{array}{l}\text { Plant } \\
\text { height }(\mathbf{c m})\end{array}$ & $\begin{array}{l}\text { Leaf } \\
\text { length(cm) }\end{array}$ & $\begin{array}{l}\text { Leaf } \\
\text { width(cm) }\end{array}$ \\
\hline CO1 & 63 & 7.50 & 2.10 \\
CO2 & 65 & 11.20 & 3.40 \\
K1 & 97 & 11.50 & 3.80 \\
K2 & 98 & 11.30 & 3.10 \\
KKM1 & 78 & 12.40 & 3.40 \\
PKM1 & 63 & 11.70 & 3.70 \\
PMK1 & 65 & 12.50 & 3.60 \\
PLR1 & 68 & 13.50 & 3.20 \\
CCH1 & 60 & 7.80 & 2.30 \\
CA97 & 58 & 7.60 & 1.80 \\
Sln1 & 59 & 7.70 & 1.90 \\
\hline
\end{tabular}


Fig.1 Dendrogram representing the grouping of eleven chilli genotypes formed through UPGMA based on morphological markers

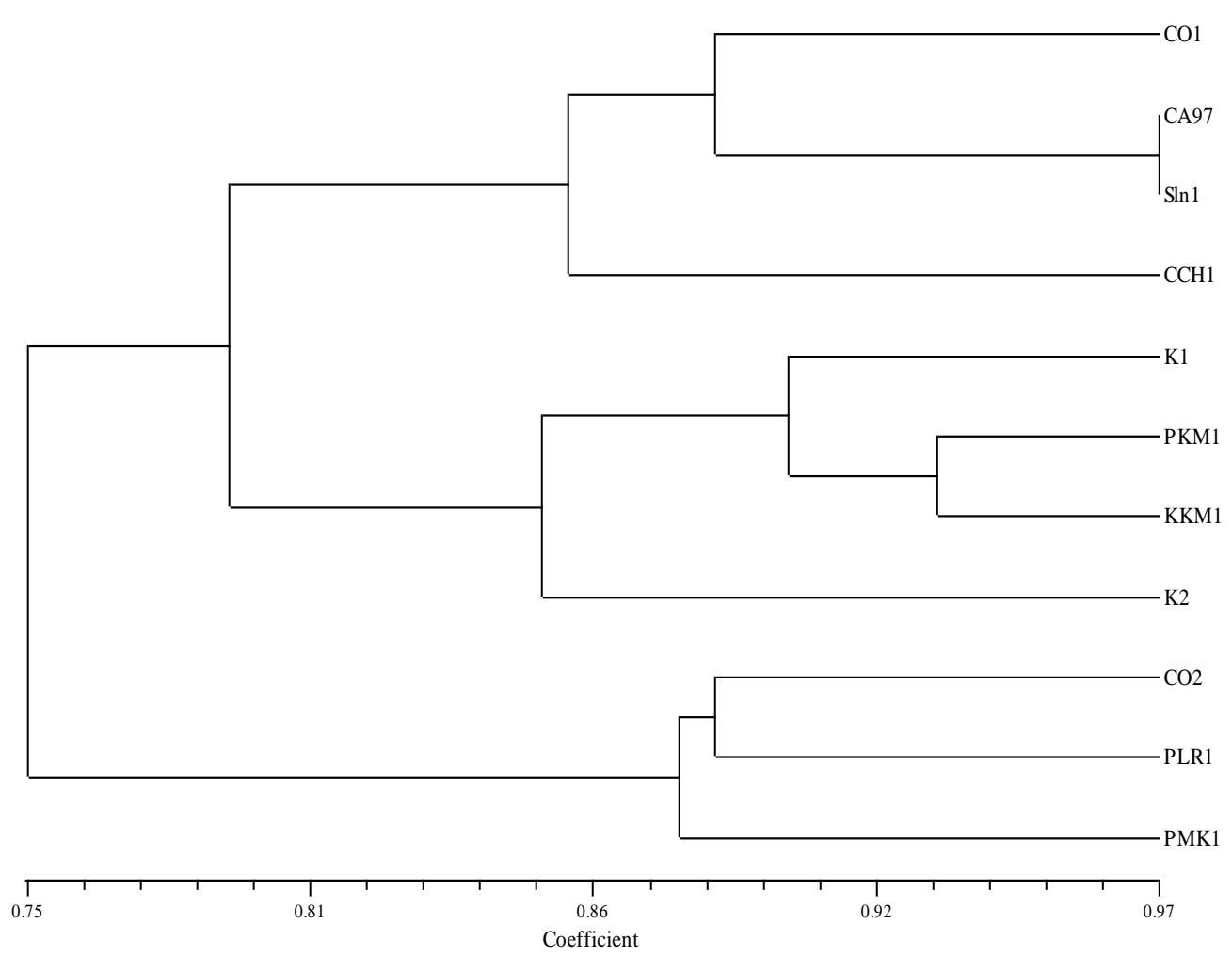

Cluster analysis showed that the eleven genotypes were grouped into two major clusters at $76 \%$ similarity level. The similarity matrix coefficient ranged from $76 \%$ to $97 \%$ with an average of $87 \%$. In cluster 1 , three genotypes were formed a separate and sub clusters with the similarity coefficient ranged from $87.5 \%$ to $97.0 \%$ in the dendrogram (Fig. 1). At the $87.5 \%$ and $85.5 \%$ similarity level PMK1, PLR1 and CO2 diverged from other genotypes. The rest of the eight genotypes were formed a second cluster and third clusters with similarity coefficient ranged from $80 \%$ to $97 \%$. The female $(\mathrm{S} \ln 1)$ and male (CA97) parents of $\mathrm{CCH} 1$ hybrid were tied i.e. these genotypes placed at same level of $97 \%$ similarity. The female had high similarity coefficient with the rest of the genotypes studied $(87.1 \%, 75.75 \%, 77.1 \%$, $80 \%, 67.1 \%, 80 \%, 70 \%, 75.1 \%, 87.1 \%$ and $97 \%$ similarity with $\mathrm{CO} 1, \mathrm{CO} 2, \mathrm{~K} 1, \mathrm{~K} 2$,
PLR1, PKM1, PMK1, KKM1, CCH1 and CA97 respectively). The dendrogram result revealed that genotypes hybrid and its parental lines were grouped as one cluster and other varieties were grouped as the second and third clusters. The above mentioned morphological characters were useful for the identification of genotypes at vegetative and flowering stage itself. Hence, this study was useful for the characterization and identification of among chilli genotypes before the fruiting stage defeating the need to wait till maturity as chilli possesses duration of more than one hundred twenty days.

In conclusion, from this study, it is concluded that the 11 chilli genotypes can be effectively distinguished by its' morphological characters. Out of 33 morphological characters, only 8 qualitative morphological characters viz., intensity of anthocyanin 
coloration of nodes, stem pubescence, plant growth habit, leaf color, leaf pubescence, flower position, anther colour and calyx annular constriction and 3 quantitative characters viz., leaf length, width and plant height were found as the important morphological characters for its varietal identification. This study provides an idea to conduct DUS testing for chilli genotypes, which is lacking in The National Test Guidelines. Further studies are warranted to fruits and seeds morphological characters.

\section{References}

Arunkumar, M.B., R.J. Bherry, M. Dadlani, A. Varier and S.P. Sharma. 2004. Characterization of pearl millet hybrids and parental lines using morphological characters. Seed Res., 32(1): 15-19.

Eevera, T. 2003. Morphological, biochemical and molecular characterization of rice varieties and hybrids, 145-178. Ph.D. Diss., Tamil Nadu Agricultural University, Coimbatore, 2003. 166 pp.

Escribano, M.R., M. Santalla and A.M. Ron. 1997. Genetic diversity in pod and seed quality traits of common bean populations from Northwestern Spain. Eupytica., 93: 71-81.

Galvan, M.Z., M.C. Menendez-Sevillano, A.M. De Ron, M. Santalla and P.A, Balatti. 2006. Genetic diversity among wild common beans from Nortwesthern Argentina Based on MorphoAgronomic and RAPD data. Genet. Reseour. Crop Evol., 53: 891-900.

Hasan, M.J., M.U. Kulsum, M.Z. Ullah, M. Manzur Hossain and M. Eleyash Mahmud. 2014. Genetic diversity of some chili (Capsicum annuum L.) genotypes. Int. J. Agril. Res. Innov \& Tech., 4(1): 32-35.

Ince, A.G., M. Karaca and A.N. Onus. 2009. Development and utilization of diagnostic DAMD-PCR markers for
Capsicum accessions. Genet. Res. Crop Evol., 56: 211-221.

Jaccard, P. 1908. Nouvelles recherches sur la distribution florale. Bul. Soc. Vaudoise Sci. Nat., 44: 223-270.

Jain, S.K., D. Khare, M.S. Bhale and N.D. Raut. 2002. Characterization of mung bean varieties for verification of genetic purity. Seed Tech. News, 32(1): 200201.

Kumar, R., N. Dwivedi, R.K. Singh, S. Kumar, V.P. Rai and M. Singh. 2011. A Review on Molecular Characterization of Pepper for Capsapcin and Oleoresin. Int. J. Plant Breed. Genet., 5(2): 99110.

Manju, P.R. and Sreelathakumary. 2004. Genetic divergence in hot chilli. Capsicum Egg Plant Nwsl., 23: 69-72.

Manjunath Reddy, C.A. 2005. Varietal characterization by morphological, chemical and electrophoresis of cotton (Gossypium spp.) hybrids and their parents, 103-127. M.Sc. Diss., University of Agricultural Sciences, Dharwad, 2005.119 pp.

Mate, S.N. and V.R. Shelar. 2006. Morphological characterization of sorghum hybrids and their parental lines. Abstract XII National Seed Seminar, ANGRAU, Hyderabad, p.175176.

Moscone, A., M.A. Scaldaferro, M. Grabiele and N.M. Cecchini. 2007. The evolution of Chili Peppers (Capsicum Solanaceae): a cytogenetic perspective. Acta Hort., 745: 137-170.

Paul, A.C.M., D. Deinum, L. Cavellini, D. Andre, Moretti, R. Sophic, V.D.S. Hanneke, C. David, P. Fernando, C. Cecile, M. Rene, S. Diederik, C. Carole and V. Ben. 2010. Development and evaluation of robust molecular markers linked to disease resistance in tomato for distinctness, uniformity and stability testing. Theor. Appl. Genet., 120: 655- 
664.

Payakhapaab, S., D. Boonyakiat, and M. Nikornpun. 2012. Genetic Evaluation and Physico-chemical Properties of Chillies (Capsicum annuum L.). J. Agri. Sci., 4 (12); 253-260

Prakash, S. and N.C. Singhal. 1997. Characterization of some Indian pea (Pisum sativum L.) cultivars. Seed Res., 25 (1): 53-58.

Qaryouti, M.M., H. Hamdan and M. Edwan. 2003. Evaluation and characterization of Jordanian pepper (Capsicum annuum L.) landraces. Capsicum Eggplant Nwsl., 22: 21-24.

Rai, N., K.S. Pramod, C.R. Avinash, R. Ved Prakash and Major Singh. 2011. Genetic diversity in Indian bean (Lablab purpureus) germplasm based on morphological traits and RAPD markers. Indian J. Agri Sci., 81(9): 8016.

Ravi, M. 2000. Molecular markers based varietal profiling and monitoring in rice (Oryza sativa L.), 145- 163. M.Sc. Diss., Tamil Nadu Agricultural University, 2000.152 pp.

Rohlf, F.J. 2002. NTSYS-pc: Numerical taxonomy system ver. 2.1. Exeter Publishing Ltd., Setauket, New York.

Sood, S., R. Sood and Vidyasagar. 2011a. Morphological characterization of bell pepper (Capsicum annuum var. grossum) genotypes and their application for distinctness, uniformity and stability testing. Indian J. Agric. Sci., 81(3): 240-6.

Sripunitha, A. 2012.Morpho-Molecular Characterization of certain rice varieties, 133-169. Ph.D. Diss., Agricultural College and Research Institute, Madurai, 2012. 154 pp.

Sudre, C.P., L.S.A. Goncalves, R. Rodrigues, A.T. Do Amaral Junior, E.M. RivaSouza and C. Dos, S. Bento. 2010. Genetic variability in domesticated Capsicum spp as assessed by morphological and agronomic data in mixed statistical analysis. Genet. Mol. Res., 9 (1): 283-294.

Sudre, C.P., L.S.A. Goncalves, R. Rodrigues, A.T. do Amaral Junior, E.M. RivaSouza and C. dos S. Bento. 2010. Genetic variability in domesticated Capsicum spp as assessed by morphological and agronomic data in mixed statistical analysis. Genet. Mol. Res., 9(1): 283-294.

The Protection of Plant Varieties and Farmers Rights Bill. 2001. Seed Association of India, Newsl., 15: 1-35.

Wang, D. and P.W. Bosland. 2006. The Gene of Capsicum. Hortsci, 41(5): 11691187.

\section{How to cite this article:}

Padma, J., S. Anbu and Sivasubramaniam, K. 2017. Efficacy of Morphological Characters for Varietal Identification of Chilli. Int.J.Curr.Microbiol.App.Sci. 6(2): 690-700. doi: http://dx.doi.org/10.20546/ijcmas.2017.602.078 